\title{
Comissões e Partidos Políticos na Câmara dos Deputados: Um Estudo sobre os Padrões Partidários de Recrutamento para as Comissões Permanentes*
}

\author{
Gustavo Müller
}

\section{INTRODUÇÃO}

$\mathrm{O}$ objetivo deste artigo é analisar os padrões partidários de recrutamento de titulares para as Comissões Permanentes da Câmara dos Deputados na legislatura de 1995/1999, a fim de verificar a existência de perfis diferenciados no tocante às trajetórias político-partidárias dos indicados para as mesmas.

A hipótese adotada neste trabalho é a de que o sistema de comissões permanentes leva os partidos a recrutar parlamentares que, por sua lealdade política, possam maximizar a execução das metas de seus partidos nas comissões estratégicas. É importante salientar que a perspectiva adotada para o termo lealdade política difere daquela assumida para o termo fidelidade partidária. Este último pode ser visto como um conceito que, de modo geral, é utilizado para mensurar a disciplina partidária, a partir de votações nas quais os votos dos deputados seguem a orientação do líder do partido, atribuindo aos mesmos graus diferenciados

\footnotetext{
* Este artigo foi extraído de minha Dissertação de Mestrado em Ciência Política (Partidos e Comissões: Um Estudo sobre os Padrões Partidários de Recrutamento para as Comissões Permanentes da Câmara dos Deputados-1995/1999) apresentada no Programa de Pós-Graduação em Ciência Política da Universidade Federal do Rio Grande do Sul em abril de 2002.
}

DADOS - Revista de Ciências Sociais, Rio de Janeiro, Vol. 48, no1, 2005, pp. 371 a 394. 


\section{Gustavo Müller}

de fidelidade partidária. Embora válido como instrumento de análise da composição das comissões, a fidelidade partidária somente pode ser mensurada no decorrer de cada legislatura, portanto, não capta os critérios observados quando do recrutamento para as comissões na fase inicial das legislaturas.

Uma alternativa seria adotar um critério "retrospectivo" de fidelidade partidária, ou seja, observar as votações dos deputados nas legislaturas anteriores, mas surgiram dois problemas de ordem metodológica: primeiro, tal critério não poderia ser aplicado aos deputados estreantes na Câmara, visto que no Brasil a taxa de renovação do Legislativo assume proporções significativas, atingindo o índice médio de $40 \%$ a cada pleito, esses parlamentares ficariam fora do universo pesquisado (Santos, 2000:70). O segundo problema diz respeito à forma de tratamento que seria dada aos deputados que migraram de partido.

O conceito de lealdade política foi utilizado em uma tentativa de contornar esses problemas. O suposto adotado é que a trajetória político-partidária dos deputados pode ser um fator importante na decisão do líder partidário na composição das comissões. Assim sendo, um parlamentar que tenha passado por vários partidos, mas permanecido no mesmo bloco ideológico, pode ser mais "confiável" do que um parlamentar que possua uma trajetória de migrações interblocos.

Os procedimentos metodológicos buscaram captar os critérios que teriam orientado o recrutamento para as comissões no início da legislatura analisada. A justificativa para tanto está no fato de que, mesmo ocorrendo uma permanente mudança na composição das comissões no decorrer das legislaturas, o recrutamento inicial pode ser visto como um "posicionamento estratégico", no qual os partidos procuram preencher as vagas nas comissões estratégicas para seus objetivos com deputados mais leais. O conjunto das comissões foi agrupado em quatro subconjuntos para fins de análise:

a) Comissões de ordem econômica e administrativa: Comissão de Economia, Indústria e Comércio - CEIC, Comissão de Finanças e TributaçãoCFT, Comissão de Fiscalização Financeira e Controle - CFFC e Comissão de Trabalho, Administração e Serviço Público - CTASP;

b) Comissões de ordem social: Comissão de Defesa do Consumidor, Meio Ambiente e Minorias - CDCMAM, Comissão de Educação, Cultura e 
Desporto - CECD, Comissão de Seguridade Social e Família - CSSF e Comissão de Direitos Humanos - $\mathrm{CDH}$;

c) Comissões de foco regional, em outros termos, comissões cujas atribuições específicas podem torná-las mais ou menos interessantes para as diferentes regiões, de acordo com suas características econômicas: Comissão de Agricultura e Política Rural - CAPR, Comissão de Ciência, Tecnologia, Comunicação e Informática - CCTCI, Comissão de Desenvolvimento Urbano e Interior - CDUI, Comissão de Viação e Transporte - CVT e Comissão de Minas e Energia - CME;

d) Comissões de política externa: Comissão de Defesa Nacional - CDN e Comissão de Relações Exteriores - CRE.

A Comissão de Constituição e Justiça e de Redação - CCJR representa um caso à parte. Por ser uma instância do Legislativo com poderes para barrar projetos de lei e emendas constitucionais, torna-se estratégica para todos os partidos.

Na segunda parte deste artigo é feita uma síntese das abordagens existentes na literatura especializada nacional e internacional acerca do Legislativo, seguida de uma análise dos indicadores referentes às trajetórias político-partidárias dos deputados federais da legislatura em questão. Por fim, na parte conclusiva é feito um retorno ao debate teórico, procurando identificar as possíveis contribuições deste trabalho. Os indicadores construídos dizem respeito às origens partidárias (primeira filiação), número de filiações, coerência ideológica e participação em diretórios partidários, e visam captar indicadores que sinalizem as estratégias dos partidos para a composição de tais comissões.

\section{LEGISLATIVOS. COMISSÕES E SUAS ABORDAGENS}

Um dos problemas que se colocam para quem pesquisa a dinâmica dos Legislativos é saber quais são os atores relevantes em termos de poder decisório e poder de agenda, bem como de que maneira esses atores estabelecem suas estratégias para atingirem seus objetivos. Nesse sentido, o debate em torno do recrutamento para as comissões adquire singular importância por revelar aspectos intrinsecamente ligados ao processo legislativo e, por conseguinte, à prática representativa.

Nas abordagens da literatura acerca do Legislativo, a referência ao Congresso norte-americano ocorre quase de forma ritual, dado o volume da produção acadêmica sobre o tema. Mesmo antes do 


\section{Gustavo Müller}

neo-institucionalismo, pesquisadores norte-americanos consideravam a estrutura institucional uma variável de significativa relevância para a compreensão do comportamento empreendido pelos atores. Os estudos de Polsby (1968) e Clapp (1962) retratam de modo ilustrativo a perspectiva institucional, no primeiro caso, salientando o fortalecimento dos critérios endógenos de recrutamento para postos-chave no interior do Legislativo, no segundo, a influência da organização legislativa na especialização do trabalho parlamentar. Em outras palavras, tanto Polsby, como Clapp constatam que, ao longo do tempo, a sedimentação das regras do jogo reduziram os espaços de "ingresso lateral" , transformando a seniority em critério de "promoção" interna, seja pela deferência prestada por "novatos", seja pelo acúmulo de conhecimento específico obtido por determinado parlamentar por meio do trabalho em comissões.

Mais recentemente, o debate sobre o papel desempenhado pelas comissões no processo legislativo foi sistematizado pelo neo-institucionalismo em três linhas distintas, a saber: informacional, distributivista e partidária (Limongi, 1994). Cada uma atribui diferentes funções às comissões. As duas primeiras concentram seu foco na grande autonomia delas e na vigência de critérios auto-seletivos na composição das mesmas, seja pelas especificidades das informações contidas nestas, requerendo alto grau de expertise, seja pelas conveniências eleitorais para a reeleição de parlamentares. Já a terceira linha ressalta o papel dos partidos no controle do recrutamento para as comissões.

Resumida por Keith Krehbiel (1991), a linha informacional argumenta que, quando o pêndulo da assimetria de informações entre plenário e comissões favorece estas últimas, há um destaque do seu papel no processo legiferante. Sendo assim, a permanência em determinada comissão geraria parlamentares especializados, reforçando o poder das comissões em relação ao plenário e constrangendo os partidos através da regra de seniority, uma vez que a violação desta poderia acarretar "incerteza" ao plenário no que diz respeito aos possíveis resultados de determinada legislação.

A linha distributivista busca explicar o comportamento no interior do Legislativo a partir do interesse individual de cada parlamentar por sua reeleição, o que tornaria o processo legiferante o resultado do equilíbrio das preferências individuais. Para a linha distributivista, o recrutamento para as comissões ocorreria de modo auto-seletivo, sendo que 
os parlamentares escolheriam as comissões visando o atendimento às suas bases eleitorais (Limongi, 1994:8). O quadro institucional, para a linha distributivista, seria o fator de estabilidade, reduzindo as incertezas quanto ao leque de escolhas dos atores, ou, nas palavras da Schepsle (1995:283), structure induced equilibrium.

A versão partidária, representada por Cox e McCubbins, ressalta o papel do partido como instrumento de dissolução de conflitos. Contrariamente às duas primeiras linhas, que buscam explicar o comportamento dos parlamentares no interior do Legislativo e, por conseguinte, o papel das comissões, a partir da autonomia das mesmas, com largo espaço para as preferências individuais, a linha partidária parte de uma releitura das teorias da organização industrial, para demonstrar a importância da autoridade central. No melhor estilo hobbesiano, a autoridade central, exercida por meio das prerrogativas regimentais, possibilita aos líderes o controle das indicações para as comissões e o poder de agenda no processo legislativo (Cox e McCubbins, 1993:85).

Uma das formas de materialização do poder dos líderes, segundo esses autores, está na prerrogativa de selecionar os projetos que irão à apreciação do plenário (idem:236). Tal procedimento guarda forte semelhança com o caso brasileiro, no qual a pauta da "Ordem do Dia" é estabelecida por acordo de líderes, cabendo a estes indicar quem dos seus respectivos partidos fará uso da palavra no "Grande Expediente".

Além dos poderes regimentais, os líderes podem dispor de outros mecanismos para influenciar o comportamento de seus liderados que não impliquem necessariamente em punição, mas no controle da distribuição de informações e benefícios. Kiewiet e McCubbins (1991) afirmam que os partidos representam "investimentos comuns" e significam mais do que agregar um conjunto de preferências individuais. Através do label partidário é possibilitado ao eleitor o conhecimento, de forma resumida e antecipada, das posições de seus candidatos. A cisão entre "sulistas e nortistas" no Partido Democrata norte-americano ilustra essa perspectiva.

Conhecido tradicionalmente por sua plataforma liberal, no sentido norte-americano do termo, sua seção "sulista" apresentava uma postura acentuadamente conservadora, destoante do label do partido. Todavia, a dissidência sulista não atingiu proporções fortes o suficiente para se manter como linha, ainda que minoritária, do partido (idem:40). A partir da derrota desta facção, foi possível aos líderes do Partido De- 


\section{Gustavo Müller}

mocrata a retomada do controle da linha partidária no Legislativo, reduzindo a autonomia das comissões através da quebra da regra de seniority (Cox e McCubbins, 1993:56), o que sugere ser factível a hipótese de que os partidos adotam critérios estratégicos de recrutamento para as comissões.

Não obstante as limitações que as três linhas neo-institucionalistas possuam, seus instrumentais teórico e empírico fornecem um pano de fundo a partir do qual podem ser extraídas questões gerais a respeito de enfoques e metodologias de análise relacionadas aos Legislativos. O reconhecimento do background neo-institucionalista, contudo, não isenta o pesquisador da responsabilidade de buscar novos caminhos que aumentem o potencial explicativo de pesquisas que visem mensurar o desempenho institucional dos Legislativos.

A análise de Epstein e O'Halloran (1999:163, 194-195) apresenta aspectos relevantes para a construção de modelos explicativos a partir das teorias neo-institucionalistas. No que tange aos objetivos deste artigo, cabe citar duas assertivas que, de certo modo, reforçam os argumentos aqui arrolados em direção à veracidade da hipótese de padrões de recrutamento para comissões balizados, preponderantemente, por critérios partidários. A primeira assertiva diz respeito aos incentivos para que se adote um determinado tipo de organização do Legislativo. Segundo os autores, a predominância de sistemas de comissões semelhantes aos modelos distributivista ou informacional pode derivar de incentivos criados a partir do arcabouço constitucional e da separação dos Poderes, e não da ação direta dos legisladores. A segunda assertiva conclui que as três linhas neo-institucionalistas não são mutuamente exclusivas. Em outras palavras, os autores afirmam que as comissões podem exercer tanto as funções distributivistas e informacionais, como partidárias, dependendo dos objetivos dos atores.

Embora não seja meu objetivo aqui o debate em torno da relação entre os Poderes, as duas assertivas de Epstein e O'Halloran apontam para perspectivas teóricas que podem ser vistas como elementos complementares na análise do Legislativo brasileiro, visto que, por força constitucional, o presidente da República possui a prerrogativa de intervir no processo legislativo através das "Medidas Provisórias" e dos "Pedidos de Urgência", sendo este último um instrumento também disponível aos líderes, o que esvazia o poder e a autonomia das comissões. 


\section{O Debate Brasileiro}

O interesse acadêmico pelo desempenho das instituições, sobretudo legislativas, é muito recente no Brasil. Não obstante, quando eram feitas referências às instituições brasileiras, seus conteúdos traziam, implícita ou explicitamente, advertências relacionadas ao risco iminente de colapso do regime democrático provocado por efeitos deletérios à boa governança advindos da combinação de institutos como presidencialismo, voto proporcional de lista aberta e federalismo.

De modo geral, diagnósticos salientando aspectos negativos do sistema partidário brasileiro são encontrados em observadores estrangeiros, embora existam pesquisadores brasileiros que, em determinado momento, compartilharam a tese da incipiência do sistema partidário no Brasil (Lamounier e Meneguello, 1986). O ponto em comum desses diagnósticos é a incapacidade dos partidos de exercerem a função representativa na arena legislativa devido à permissividade do sistema eleitoral (Mainwaring, 1999), aos conflitos distributivos provocados pelo comportamento individualista dos parlamentares que, em virtude da busca de recursos públicos para suas bases eleitorais por meio de política pork barrel, tornariam de tal forma elevados os custos das negociações, que o regime democrático seria inviabilizado por uma paralisia decisória (Ames, 2001), ou ainda, devido à falta de investimento dos parlamentares em suas carreiras no Legislativo, e à utilização deste como um meio para a conquista de cargos nos executivos estaduais e municipais (Samuels, 2003). Contudo, a realidade encontrada por pesquisadores brasileiros mostra forte contraste com prognósticos demasiadamente pessimistas.

As análises produzidas sobre o Legislativo brasileiro podem ser situadas em dois pólos principais: de um lado, estão as abordagens que enfocam o comportamento das bancadas dos partidos nas votações em plenário; de outro, as pesquisas que estudam as dinâmicas entre partidos e comissões.

A exemplo de Cox e McCubbins, as pesquisas de Figueiredo e Limongi demonstram que, apesar do individualismo das campanhas proporcionais, a orientação do líder de bancada representa um forte elemento para a predição do comportamento de seus liderados nas votações em plenário (Figueiredo e Limongi, 1999:93). Os autores enfatizam o poder regimental dos líderes partidários no controle da agenda do Legislativo como sendo a fonte que dá aos mesmos a capacidade de impor às 
suas bancadas uma disciplina capaz de levá-las a votarem de acordo com a sua orientação.

Fabiano Santos, ao deslocar o foco do plenário para as comissões, compartilha a tese do government partidário no processo legislativo. $\mathrm{O}$ autor aponta o recrutamento para comissões como sendo uma prerrogativa exclusiva dos líderes. Estes, por sua vez, utilizam o critério da lealdade, mensurado através do comportamento dos deputados durante votações essenciais, contrabalançado pela necessidade de expertise, auferida pela formação profissional/acadêmica ou atividade econômica, no recrutamento para as comissões de controle que, segundo o autor seriam a Comissão de Constituição e Justiça e de Redação, e a Comissão de Finanças e Tributação (Santos, 2003:100-105).

Ainda com o foco nas comissões, Pereira e Mueller (2000), mesmo reconhecendo a preponderância do Executivo na iniciativa legislativa, procuram adaptar as teorias distributivista e informacional ao sistema de comissões do Legislativo brasileiro. Os pressupostos destas duas interpretações possuem como núcleo explicativo, conforme foi exposto, a preferência individual dos deputados no recrutamento para as comissões. Estas são escolhidas para que ou potencializem o atendimento às suas bases eleitorais, no caso do distributivismo, ou garantam o ganho de informações especializadas, no caso da teoria informacional. Cumpre, entretanto, salientar que soa com certa estranheza a tentativa de adaptação de modelos teóricos que pressuponham a existência de um forte sistema de comissões para analisar uma estrutura institucional cujo poder decisório se concentra no Colégio de Líderes, conferindo um reduzido espaço de autonomia para as comissões.

Os avanços teóricos produzidos por pesquisas que deram tratamento empírico sistematizado a uma volumosa massa de dados referentes ao processo legislativo permitiram que se criasse no Brasil uma agenda positiva em termos de enfoques sobre o papel desempenhado pelos partidos políticos.

\section{Trajetórias Político-Partidárias e Recrutamento para as Comissões}

Aceitas como válidas as premissas de que a atual estrutura organizacional da Câmara dos Deputados concentra nas mãos dos líderes partidários grande poder de decisão, favorecendo o controle dos partidos sobre a composição das Comissões Permanentes, e que o padrão de recrutamento possa estar relacionado com cada configuração partidária, 
esta seção se detém em indicadores que possam esclarecer as relações entre partido e padrão de recrutamento. Para tanto, três pressupostos são fundamentais: o primeiro diz respeito à homogeneidade dos partidos; o segundo trata dos vínculos entre deputado e partido; por fim, da conexão entre parlamento e estrutura partidária.

Visto que migrações partidárias constituem um traço característico do sistema partidário brasileiro (Mainwaring, 1999), as agremiações partidárias podem ser vistas, muitas vezes, como destituídas de capacidade de conduzir seus membros a executar um programa em comum. Os trabalhos de Figueiredo e Limongi (1999) e Santos (2001) constatam a redução da migração intrabloco, o que significa que, apesar das mudanças de partidos, os indivíduos tendem a conservar sua posição no espectro ideológico.

Produções recentes vêm explorando, ainda que de forma sintética, a origem e constituição dos atuais partidos (Schmitt, 2000), sobretudo dos "partidos conservadores" (Mainwaring et alii, 2000). Essa perspectiva abre possibilidades não só para análises longitudinais, comparando as gêneses dos partidos no momento de instauração do segundo ciclo multipartidário (final da década de 70), mas também possibilita a exploração analítica dos conceitos de coesão e disciplina. Bowler et alii (1999:10), citando Ozbudun, abordam a distinção entre coesão e disciplina como sendo a capacidade de ação em torno de metas em comum, no primeiro caso, e a observação das diretrizes partidárias por seus membros, no segundo. Esta perspectiva pode ser adotada para o caso brasileiro na análise da origem partidária de seus deputados.

Parte-se da hipótese de que partidos com constituições homogêneas, ou seja, formados por parlamentares oriundos do mesmo bloco ideológico, podem apresentar comportamentos mais coesos, enquanto partidos formados a partir de matrizes heterogêneas se limitam à imposição de comportamento disciplinado nas votações em plenário, tendo, portanto, um custo mais elevado para atingir suas metas. A Tabela 1 mostra os percentuais da origem partidária dos parlamentares de cada partido.

Os dados mostram um padrão de origem partidária altamente endógeno no $\mathrm{PT}^{*}$, com $79,6 \%$ de seus deputados possuindo filiação exclusiva

\footnotetext{
* Ver lista de siglas de partidos políticos com os respectivos significados ao final do artigo.
} 


\section{Gustavo Müller}

ao partido. Este padrão também é seguido pelo PC do B com 70\%. PSB e PDT mostram uma difusão maior da base de origem de seus parlamentares, chamando a atenção, no caso do PDT, a porcentagem significativa de deputados com origem na UDN, Arena, PDS e PFL, que somados atingem $18,1 \%$.

Por sua vez, PFL, PPR e PTB destoam em níveis de homogeneidade. O PFL possui deputados oriundos de três grandes bases partidárias: Arena, 24,7\%; PDS, 21,3\%; e PFL, 27\%. O PPR, embora possua percentuais relativamente elevados de membros com filiações na Arena $(21,2 \%)$ e PDS $(15,4 \%)$, mostra maior heterogeneidade na sua constituição, característica esta acompanhada pelo $\mathrm{PTB}$, com $21,9 \%$ de parlamentares com filiação exclusiva e apenas $6 \%$ de membros oriundos do antigo PTB.

O PMDB e o PSDB também são similares na difusão da origem de seus deputados, embora esta seja mais acentuada no primeiro que, ainda assim, dispõe de $42,1 \%$ de membros com filiação exclusiva, enquanto o PSDB dispõe de $28,1 \%$.

Evidentemente, ao se tratar de membros com filiação partidária exclusiva, deve-se ter em conta as disparidades no tempo de existência de cada partido. Do conjunto de partidos acima listados, o PSDB, fundado em 1988, é a sigla que teve o ingresso mais tardio na arena eleitoral, tendo estreado em 1989. Já o PMDB, o PDT e o PT ingressaram na arena eleitoral em 1982.

Com base nos dados disponíveis no Repertório Biográfico (Deputados Brasileiros, 1997) foi quantificado o número de filiações partidárias de cada parlamentar para mensurar os vínculos partidários, e criado um indice de coerência ideológica para cada um dos casos. Este índice possui o nível alto (1), médio (2) e baixo (3), sendo os partidos agrupados no espectro esquerda, centro e direita, conforme sugerido por Figueiredo e Limongi (1999:78), na seguinte ordem: direita - PDS/PPR, PFL, PTB; centro - PMDB, PSDB; e esquerda - PDT e PT.

O critério para atribuir uma nota dentro do índice de coerência ideológica foi a observação do contexto político e do padrão das migrações partidárias. Para os parlamentares que migraram de um partido situado à esquerda para um partido à direita e vice-versa, o valor atribuído foi baixo. Para os que migraram dos extremos em direção ao centro ou em movimentação oposta (do centro para a direita ou esquerda), o valor 
Comissões e Partidos Políticos na Câmara dos Deputados...

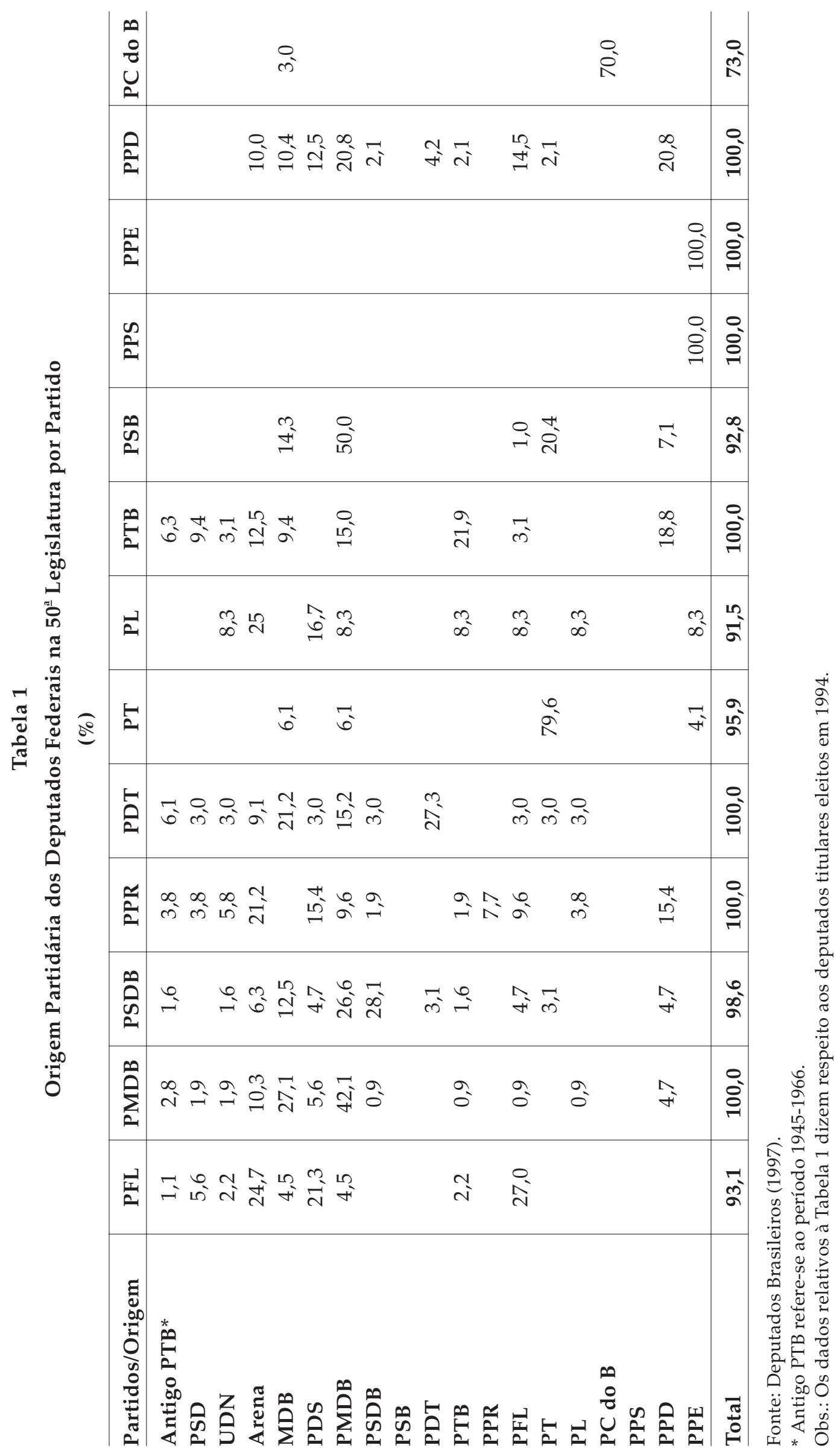




\section{Gustavo Müller}

atribuído foi médio e, finalmente, para as migrações dentro das mesmas famílias partidárias, o valor dado foi alto. Casos especiais foram encontrados por parte de deputados que migraram do MDB para a Arena, recebendo o valor baixo, pois foi considerado o contexto plebiscitário durante o regime militar.

Tanto o índice de coerência ideológica, como o número de filiações partidárias visam mensurar a permanência nos blocos ideológicos e a distribuição dos deputados nas Comissões Permanentes, de acordo com sua lealdade política. Como já foi dito na introdução, o termo lealdade política pretende captar critérios de seleção que extrapolem a idéia tradicional de lealdade ou fidelidade partidária, noções de modo geral aplicadas ao comportamento dos parlamentares durante as votações no Legislativo.

A hipótese aqui é a de que, com o conhecimento da trajetória partidária dos deputados, os líderes partidários têm condições de avaliar o "grau de confiança" que pode ser atribuído aos componentes de suas bancadas. O raciocínio aplicado é análogo ao proposto por Tsebelis ao analisar as estratégias da direção do Partido Trabalhista Britânico para a designação de candidatos aos distritos eleitorais.

Segundo Tsebelis (1998:121), o mecanismo de seleção dos candidatos envolve um raciocínio estratégico, no qual a direção partidária identifica os distritos eleitorais onde tradicionalmente o Partido Trabalhista é vitorioso. Para estas circunscrições eleitorais denominadas distritos seguros, são enviados os candidatos que mais se aproximam da linha ideológica do partido, deixando os mais radicais para os distritos onde o partido tem menores chances eleitorais.

Aplicando esse raciocínio para o recrutamento partidário, a suposição é a de que cada partido envie para as comissões que julguem de maior importância estratégica aqueles deputados que mais se aproximem da linha ideológica do partido, minimizando assim os riscos de perda de controle sobre sua bancada.

As Tabelas 2 e 3 mostram a distribuição dos índices de coerência ideológica e a média de filiações partidárias encontradas em cada comissão, respectivamente. No caso do PPR, optou-se por quantificar as filiações dos deputados oriundos do PDS, uma vez que as mudanças na denominação das legendas partidárias são, geralmente, precedidas de ci- 
sões internas, levando muitos correligionários a optar pela migração para outras agremiações políticas.

Mesmo reconhecendo as imprecisões que podem estar embutidas nesses indicadores, leva-se em conta a possibilidade de explicações complementares para que se possa ter uma visão mais clara das estratégias partidárias na composição das comissões.

Os indicadores parecem confirmar a hipótese de que trajetórias partidárias são observadas no recrutamento para as comissões. O PFL destaca-se, pois, mesmo tendo uma bancada maior do que a do PT, apresenta um índice médio de coerência ideológica muito próximo ao do PT (1,1 e 1, respectivamente). As médias do PFL encontradas nas comissões mostram um desvio mais acentuado na CDCMAM $(1,50)$. Um fato importante a ser notado está na simetria dos índices de coerência ideológica e média de filiações partidárias encontradas na CCJR, CAPR, CFT, CFFC e CTASP em relação à média partidária (última coluna à direita das Tabelas 2 e 3), o que mostra o caráter estratégico destas comissões para os pefelistas.

Ainda no pólo direito do espectro ideológico, PTB, PPR e PPD apresentam desvios bastante acentuados em relação ao PFL, tanto no que diz respeito à média de filiações como aos índices de coerência ideológica, o que indica baixos níveis de coesão partidária. A observação da distribuição dos indices de coerência ideológica desses partidos mostra a opção de enviar seus deputados mais fiéis para a CFFC, CDCMAM, CECD, CDUI e CRE, no caso do PTB. Já o PPR optou por um recrutamento mais leal para a CECD, CDUI e CRE, com uma média de 3 filiações. O bloco formado pelos pequenos partidos de direita, PPD, indicou seus parlamentares mais confiáveis para a CCTCI e a CDN, com 2,4 e 1 filiação (filiação exclusiva), respectivamente. Em termos de filiações partidárias, os deputados do PTB indicados para a CDCMAM e CECD são os que possuem filiação exclusiva ao partido com uma filiação.

No centro, PMDB e PSDB mostram os seguintes resultados: os mais altos índices de coerência ideológica do PMDB estão nos deputados indicados para a CEIC, CCTCI e CDUI, com uma média próxima de duas filiações, e no PSDB, para a CECD e CVT, com a mesma média de filiações. Nota-se que os dois partidos apresentam os mesmos índices médios de coerência ideológica e de filiações partidárias. 
Gustavo Müller

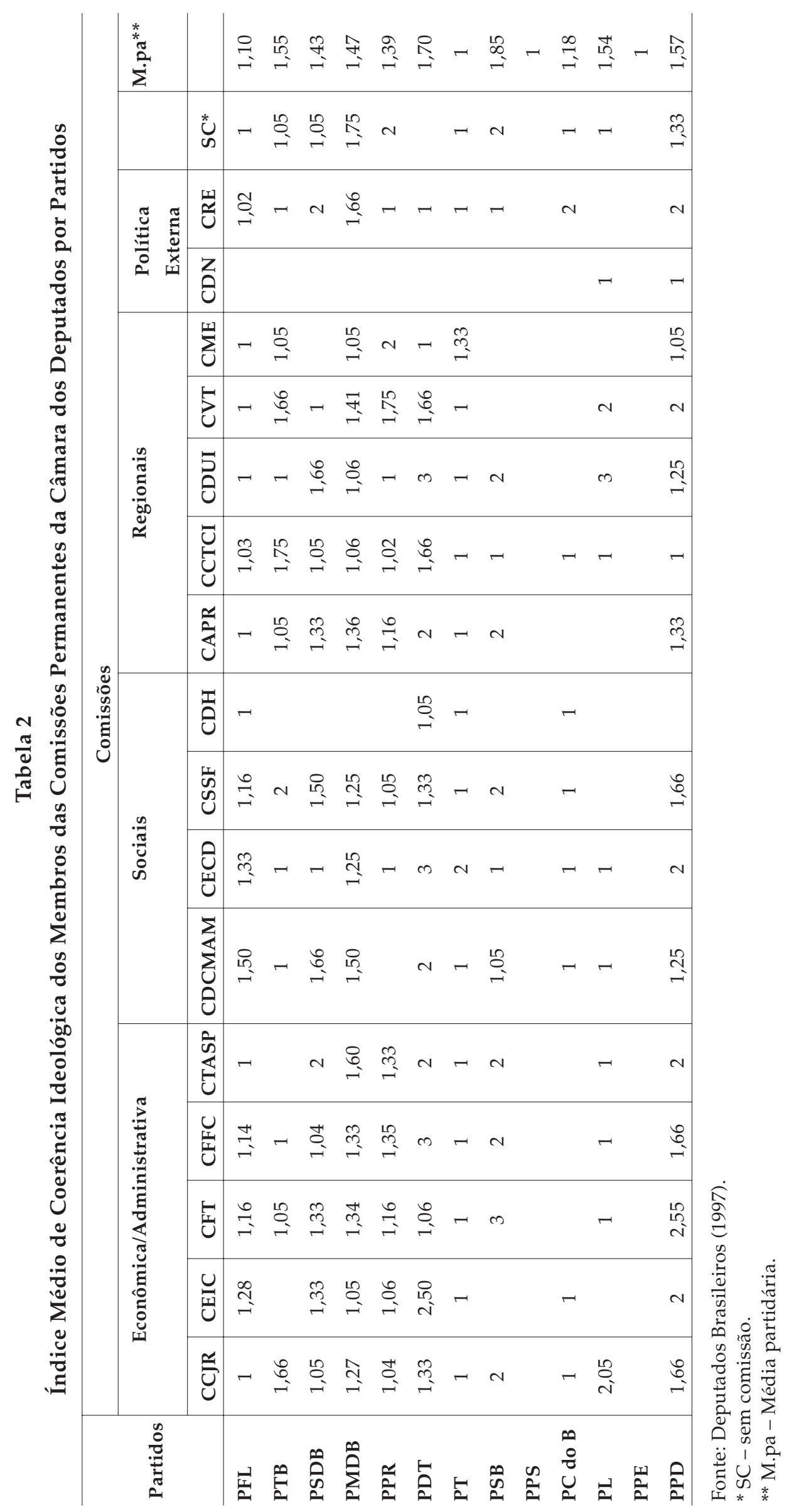


Comissões e Partidos Políticos na Câmara dos Deputados...

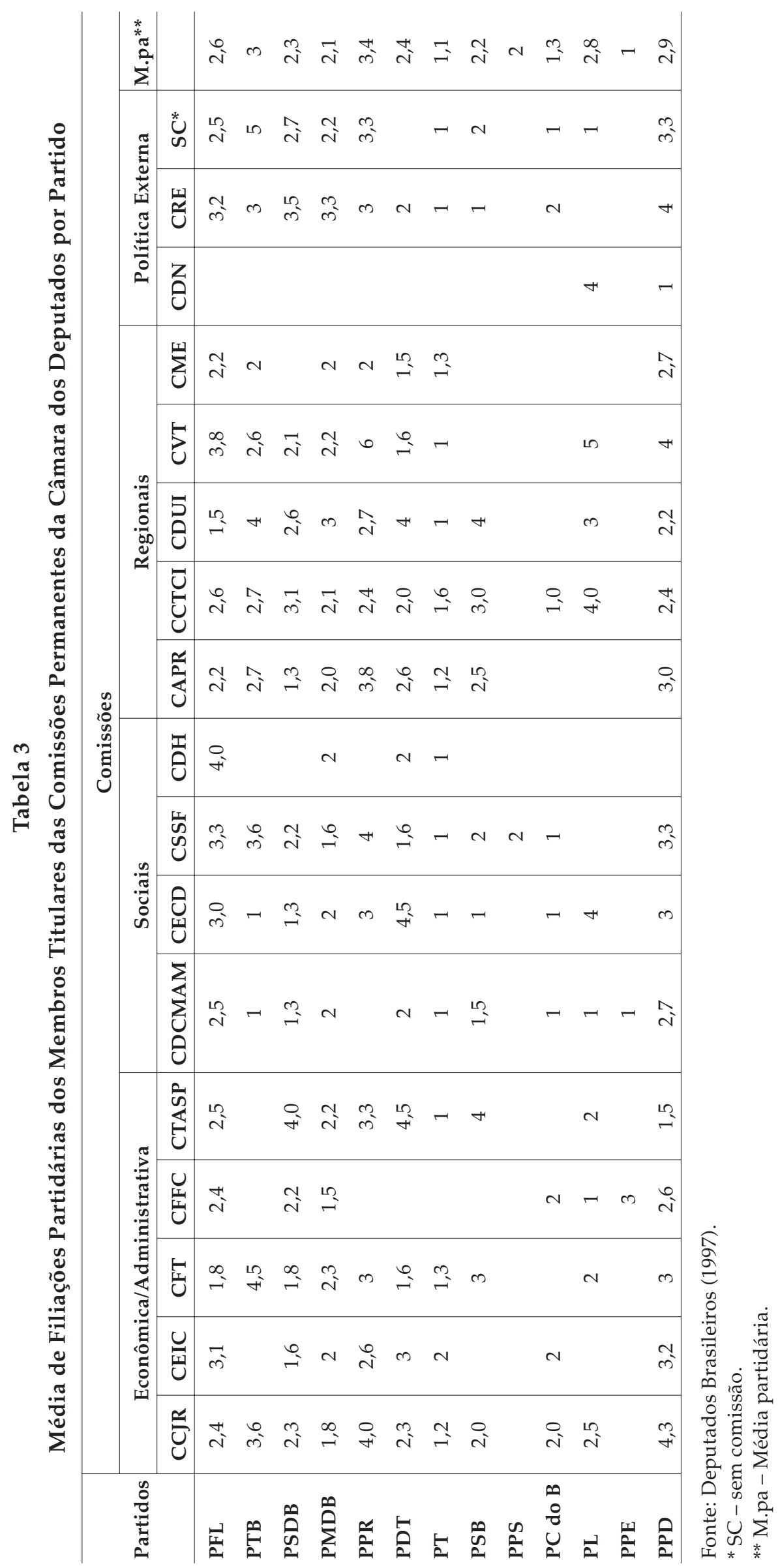


Finalmente, no pólo esquerdo, PDT e PSB possuem os índices mais baixos de coerência ideológica e os índices mais elevados de deputados com passagem em diversos partidos, com uma média de 2,3 filiações. OPDT concentrou seu núcleo de quadros fiéis nas CME e CRE. Já o PSB apostou nas CECD, CCTCI e CRE. PT e PC do B destacam-se como os partidos deste pólo com os níveis mais elevados de coesão e o maior recrutamento de parlamentares com filiação exclusiva ao partido.

De modo geral, é possível extrair dos dados referentes à homogeneidade, indices de coerência ideológica e número de filiações partidária a confirmação de que PFL e PT são os dois principais partidos em termos de coesão partidária, o que se reflete nos seus padrões de recrutamento, enviando para a maioria das comissões deputados que representam o perfil mediano dos membros dos seus partidos. No centro, PMDB e PSDB, em que pese o fato de o primeiro conservar-se ainda como um grande partido no que tange à sua expressão numérica, mostram uma certa volatilidade em termos dos vínculos partidários de suas bancadas, com padrões heterogêneos de composição parlamentar. O PDT, à esquerda, e o PPR e o PTB, à direita, acompanham os mesmos índices encontrados no centro.

A escassez de um quadro parlamentar afinado com o partido impõe um critério "econômico" mais rígido na estratégia de composição das Comissões Permanentes. Nota-se que os partidos de formação mais heterogênea, contendo parlamentares com trânsito partidário mais intenso, privilegiam determinadas comissões como estratégicas, enviando para elas seus quadros de maior fidelidade.

\section{Dirigentes Partidários e Comissões}

Um terceiro componente que pode trazer mais algumas revelações sobre as linhas adotadas pelos partidos para a composição das comissões diz respeito às relações entre Parlamento e organização partidária. Para mensurar esta relação, o procedimento adotado foi o registro da participação dos parlamentares em diretórios nacionais, ainda que em período anterior ao mandato de deputado federal, pois esta revela o grau de inserção partidária de cada membro.

Baseando-me nos conceitos de Panebianco (1990:40) referentes aos incentivos selectivos como benefícios distribuídos para poucos indivíduos, a hipótese aqui é a de que a indicação de um deputado com participação no diretório nacional de sua organização partidária para deter- 
minada comissão representa, ao mesmo tempo, um incentivo seletivo e um indicador da importância estratégica da comissão para o partido.

Os incentivos seletivos podem ser dimensionados pela projeção pública que pode estar contida na jurisdição da comissão. Uma atuação na CCJR ou nas comissões de foco econômico-administrativo pode produzir bons espaços de exposição na mídia, aumentando, assim, a popularidade de seus membros. Simultaneamente, um partido, ao colocar um membro de sua direção em determinada comissão, recebe um ganho adicional com a redução das áreas de incerteza e o aumento do controle da execução das metas partidárias. A Tabela 4 mostra a presença, nas comissões, de deputados com participação em diretórios nacionais de seus partidos.

O que é possível observar é que existe um padrão nítido na composição das comissões, a partir do qual os membros da direção nacional dos partidos são alocados. ACCJR é a comissão que agrega o maior número de atuantes em diretórios nacionais. As indicações para esta comissão, de acordo com cada partido, mostram o PT como o que mais investiu nesse critério, com quatro membros de sua direção nacional, sendo seguido pelo PFL e PMDB, a mbos com três membros.

Tomando-se as comissões por bloco, naquelas de foco econômico-administrativo encontramos a maior concentração de representantes das direções nacionais do PFL (6) e PSDB (5). O mesmo cálculo, aplicado às comissões de foco social, resulta no predomínio de membros dos diretórios nacionais do PMDB (4) e PT (4) e, nas de foco regional, encontramos o PMDB (7), com especial atenção à CCTCI, e o PFL (5), agregando maioria na CAPR. Por fim, as comissões de foco externo são as que apresentam o menor número de membros das direções nacionais dos partidos.

Cabe ainda observar que o período aqui analisado coincide com o início do primeiro mandato de Fernando Henrique Cardoso, eleito presidente com uma agenda de reformas constitucionais que visavam mudanças estruturais na economia e no Estado brasileiro, e que, ao longo desse período, o PFL desempenhou um papel hegemônico na coalizão governista, o que talvez justifique a atenção dada pelo partido às comissões de foco econômico-administrativo, nunca esquecendo, contudo, de sua base rural. Tal afirmação pode ser verificada pela maneira como estão distribuídos os dados relativos às trajetórias político-partidárias. 
Gustavo Müller

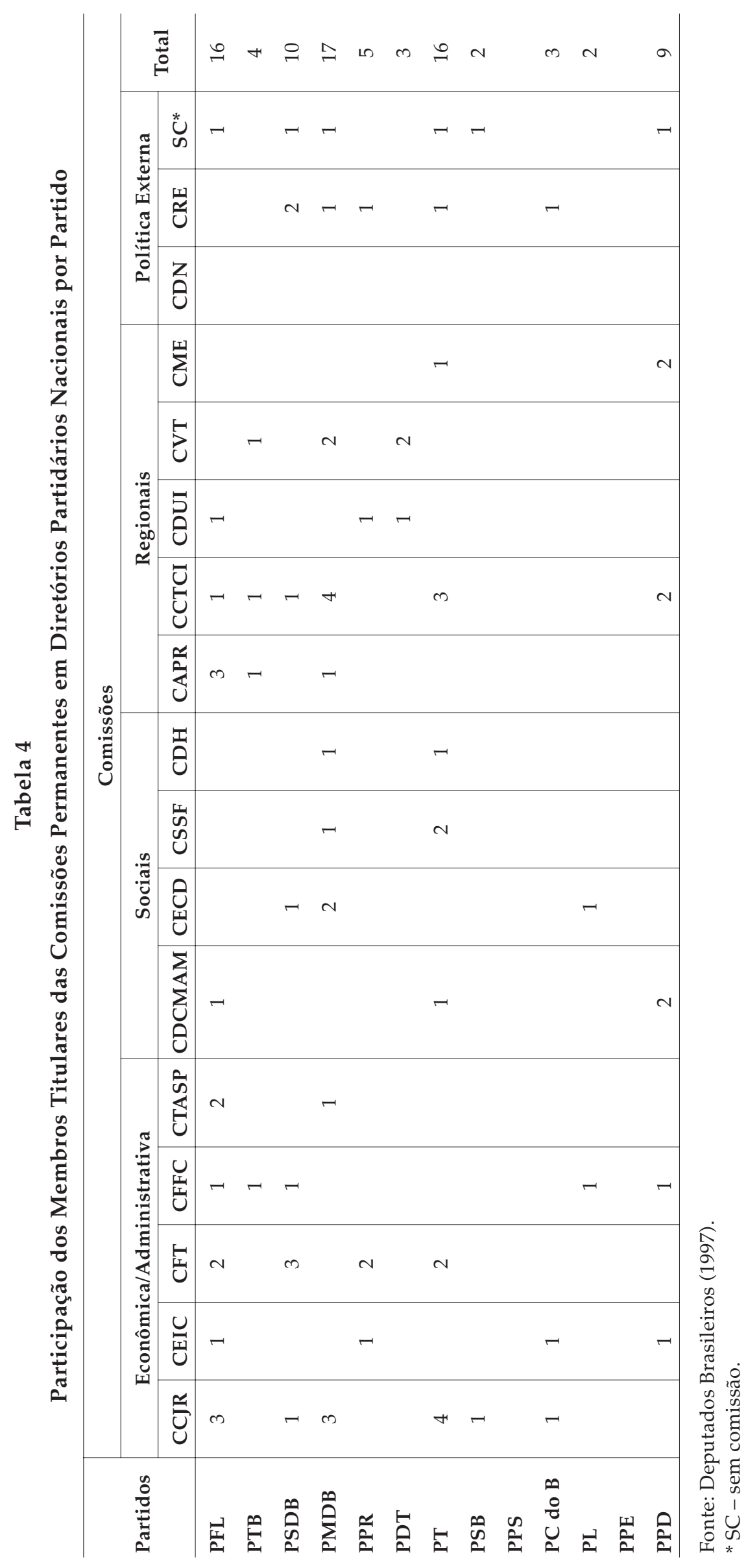


Embora contando com um percentual de deputados com filiação exclusiva similar ao PFL $(27 \%)$, o PSDB $(28,1 \%)$ e em menor escala o PTB $(21,9 \%)$ agregaram em suas bancadas deputados oriundos de diversos matizes partidários (ver Tabela 1). Tal heterogeneidade, que se refletiu nos indicadores relativos às trajetórias político-partidárias dos seus parlamentares, levou o PSDB e o PTB, que com o PFL formavam a aliança governista, a não apresentarem padrões de recrutamentos para as comissões nos quais fosse possível identificar nitidamente uma estratégia de sustentação ao governo.

OPT, como principal partido oposicionista, procurou fazer frente ao governo distribuindo seus quadros nas comissões de foco econômico-administrativo, particularmente na Comissão de Justiça, conservando, porém, sua atenção aos temas sociais. Ainda na esquerda, o PDT e o PSB apresentaram um número bastante escasso de deputados com lealdade política e vínculos partidários estáveis, o que acarretou padrões difusos de recrutamento. Cabe destacar que na CECD o baixo indice de coerência ideológica dos deputados do PDT causa surpresa, uma vez que a educação representa uma bandeira tradicional do partido.

\section{CONCLUSÃO}

Embora se tratando de um estudo de caso (composição das Comissões Permanentes da Câmara dos Deputados na 50a Legislatura 1995/1999), os resultados desta pesquisa parecem demonstrar, por intermédio de seus indicadores, que as trajetórias político-partidárias dos deputados constituem um importante elemento para o padrão de recrutamento dos membros titulares para as Comissões Permanentes.

Ainda que a dinâmica de composição das comissões assuma contornos diferenciados no decorrer de cada legislatura, com a troca permanente de cadeiras, a busca por captar os critérios iniciais de composição pode ser explicada por meio de uma metáfora militar. Tal como ocorre no planejamento de uma batalha, em que antes do combate propriamente dito as posições são ocupadas segundo uma logística, o recrutamento inicial para as comissões foi visto como um planejamento. Nesse "planejamento logístico inicial", os partidos localizam as "áreas estratégicas" para atingir suas metas e enviam seus melhores "soldados" para lá. 


\section{Gustavo Müller}

Com base nos dados relativos às trajetórias político-partidárias dos deputados, como origem partidária, índices de coerência ideológica e número de filiações partidárias, a hipótese de que o sistema de Comissões Permanentes leva os partidos a selecionarem parlamentares com maior lealdade política para as comissões estratégicas pode ser considerada apropriada como orientação para futuras pesquisas visando o aprofundamento do tema.

Esses resultados encontram amparo na interpretação partidária do sistema de comissões representada por Cox e McCubbins (1993:93), no que se refere ao papel desempenhado pelos partidos no interior do Legislativo. Segundo os autores, os partidos são os principais instrumentos para a dissolução de conflitos, inclusive os de ordem distributiva.

Tal perspectiva não exclui a possibilidade de que determinadas comissões possam cumprir papéis distributivistas ou informacionais. Todavia, seguindo a linha de raciocínio de Epstein e O'Halloran (1999:168) quanto aos fatores institucionais que, mesmo sendo externos ao Parlamento, influenciam as estratégias empreendidas pelos atores no seu interior, é possível afirmar que, tanto a limitação constitucional que impede o Legislativo de criar despesas, como os instrumentos especiais de tramitação de projetos disponibilizados aos líderes e ao Executivo esvaziam o poder das comissões, o que tornam muito estreitas as chances de estas desenvolverem papéis autônomos no processo legislativo.

De forma conclusiva, os resultados obtidos nesta pesquisa sugerem que o atual modelo organizativo da Câmara dos Deputados apresenta fortes incentivos para que, a despeito das mazelas do sistema eleitoral de lista aberta, o processo legislativo seja conduzido predominantemente por partidos políticos, o que se reflete nos padrões de recrutamento para as comissões.

(Recebido para publicação em outubro de 2004) (Versão definitiva em janeiro de 2005) 


\section{REFERÊNCIAS BIBLIOGRÁFICAS}

AMES, Barry. (2001), The Deadlock of Democracy in Brazil. Michigan. University of Michigan Press.

BOWLER, Shaun, FARRELL, David e KATZ, Richard. (1999), "Party Cohesion, Party Discipline and Parliaments", in S. Bowler, D. Farrell e R. Katz (eds.), Party Discipline and Parliamentary Government. Ohio, Ohio State University.

CLAPP, Charles L. (1962), The Congressman. His Work and He Sees it. Washington, The Brookings Institution.

COX, Gary e MCCUBBINS, Mathew. (1993), Legislative Leviathan. Party Government in the House. Berkeley/Los Angeles, University of California Press.

DEPUTADOS BRASILEIROS. (1997), Repertório Biográfico 50ํㅡㄴegislatura, 1995/1999. Brasília. Câmara dos Deputados.

EPSTEIN, David e O'HALLORAN, Sharyn. (1999), Delegating Powers. A Transaction Cost Politics Approach to Policy Making under Separate Powers. Cambridge, Cambridge University Press.

FIGUEIREDO, Argelina e LIMONGI, Fernando. (1999), Executivo e Legislativo na Nova Ordem Constitucional. São Paulo, Fundação Getulio Vargas Editora.

KIEWIET, Roderick D. e MCCUBBINS, Mathew D. (1991), The Logic of Delegation. Congressional Parties and the Appropriations Process. Chicago, Chicago University Press.

KREHBIEL, Keith. (1991), Information and Legislative Organization. Michigan, University of Michigan Press.

LAMOUNIER, Bolívar e MENEGUELLO, Rachel. (1986), Partidos Políticos e Consolidação Democrática. O Caso Brasileiro. São Paulo, Brasiliense.

LIMONGI, Fernando. (1994), “O Novo Institucionalismo e os Estudos Legislativos - A Literatura Norte-Americana Recente". BIB, $\mathrm{n}^{\mathrm{o}} 37,1^{1}$ ㅇ sem.

MAINWARING, Scott. (1999), Rethinking Party Systems in the Third Wave of Democratization. The Case of Brazil. Stanford, Stanford University Press.

MENEGUELLO, Rachel e POWER, T. (2000), Partidos Conservadores no Brasil Contemporâneo. Quais São, o que Defendem, quais suas Bases. São Paulo, Paz e Terra.

PANEBIANCO, Angelo. (1990), Modelos de Partidos. Organización y Poder en los Partidos Politicos. Madrid, Alianza.

PEREIRA, Carlos e MUELLER, Bernardo. (2000), “Uma Teoria da Preponderância do Poder Executivo. O Sistema de Comissões no Legislativo Brasileiro". Revista Brasileira de Ciências Sociais, vol. 15, ํㅡㄴ 43 .

POLSBY, Nelson. (1968), "The Institutionalization of U.S. House of Representatives". American Political Science Review, vol. LXII, março.

SAMUELS, David. (2003), Ambition, Federalism and Legislative Politics. Cambridge, Cambridge University Press.

SANTOS, André Marenco dos. (2000), Não se Fazem mais Oligarquias como Antigamente. Recrutamento Parlamentar, Experiência Política e Vínculos Partidários entre De- 


\section{Gustavo Müller}

putados Brasileiros (1946-1998). Tese de Doutorado em Ciência Política, Instituto de Filosofia e Ciências Humanas/Universidade Federal do Rio Grande do Sul.

. (2001), "Sedimentação da Lealdade Partidária no Brasil: Tendências e Descompassos". Revista Brasileira de Ciências Sociais, vol. 16, no 45.

SANTOS, Fabiano. (2003), O Poder Legislativo no Presidencialismo de Coalizão. Belo Horizonte/Rio de Janeiro, Editora UFMG/IUPERJ.

SCHEPSLE, Kenneth. (1995), "Studying Institutions: Some Lessons from the Rational Choice Approach", in J. Fan (org.), Political Science in History. New York, Cambridge University Press.

SCHMITT, Rogério. (2000), Partidos Políticos no Brasil (1945-2000). Rio de Janeiro, Jorge Zahar Ed.

TSEBELIS, George. (1998), Jogos Ocultos. Escolha Racional no Campo da Política Comparada. São Paulo, EDUSP. 
LISTA DE SIGLAS DE PARTIDOS POLÍTICOS

Arena - Aliança Renovadora Nacional

MDB - Movimento Democrático Brasileiro

PC do B - Partido Comunista do Brasil

PDS - Partido Democrático Social

PDT - Partido Democrático Trabalhista

PFL - Partido da Frente Liberal

PL - Partido Liberal

PMDB - Partido do Movimento Democrático Brasileiro

PPD - Pequenos Partidos de Direita

PPE - Pequenos Partidos de Esquerda

PPR - Partido Progressista Reformador

PPS - Partido Popular Sindicalista

PSB - Partido Socialista Brasileiro

PSD - Partido Social Democrático

PSDB - Partido da Social Democracia Brasileira

PT - Partido dos Trabalhadores

PTB - Partido Trabalhista Brasileiro

UDN - União Democrática Nacional 


\title{
Gustavo Müller
}

\author{
ABSTRACT \\ Committees and Political Parties in the Brazilian House of \\ Representatives: A Study on Party Recruitment Patterns for Standing \\ Committees
}

The objective of this article is to verify the existence of party recruitment patterns for members of the Standing Committees in the Brazilian House of Representatives during the legislature from 1995 to 1999. The hypothesis is that the standing committees system leads parties to recruit Representatives who can maximize their objectives in the committees. The study's methodology involved the construction of indicators related to the Representatives' partisan political careers. The study's main conclusion is that the Representatives' partisan political careers are observed in the recruitment for committees.

Key words: Standing Committees; parties; political loyalty; legislative process

\section{RÉSUMÉ}

Commissions et Partis Politiques à la Chambre des Députés: Étude sur les Modèles des Partis en vue du Recrutement des Commissions Permanentes

Dans cet article, on cherche à vérifier l'existence de modèles posés par les partis pour le recrutement des députés destinés aux commissions permanentes à la Chambre des Députés pour la période 1995-1999. On a formulé l'hypothèse selon laquelle le système de commissions permanentes fait que les partis recrutent des députés capables d'accroître les objectifs des partis dans les commissions. Selon la démarche méthodologique adoptée, on a construit des indicateurs en rapport avec les carrières politiques des députés. On conclut que la carrière politique des députés et leur attachement aux partis sont pris en considération lorsqu'il s'agit de les recruter pour les commissions.

Mots-clé: commissions permanentes; carrières politiques et de partis; fidélité politique 